\title{
Analysis of long-term corrosion behavior in mortars containing recycled ladle furnace slag using computerized tomography and SEM
}

\author{
A. Rodríguez, S. Gutiérrez-González, M. I. Prieto, A. Cobo \\ and V. Calderón*
}

\begin{abstract}
A series of mortars subjected to accelerated corrosion in a humid environment form the basis for this study. In particular, we studied the corrosion behavior of steel reinforcement bars that were embedded in cement mortars that contained white ladle furnace slag (LFS) in partial substitution for fines and cement. The effects were observed using computerized axial tomography and scanning electron microscopy. Zones with fissures resulting from corrosion and the degree of damage due to passivation were identified from the imaging analysis. Mortars with and without white LFS behaved in a similar manner in the presence of chlorides. X-ray diffraction (XRD) analysis confirmed that the formation of different hematite and goethite-type iron oxides was mainly responsible for the corrosion that was observed.
\end{abstract}

\section{Introduction}

The corrosion resistance of reinforced concrete is a key factor affecting its durability. Poor corrosion resistance will inevitably lead to significant and expensive repair work to the concrete at a later stage. Research in the field of civil engineering [1] has focused on corrosion that is induced through the addition of chlorides to reinforced concrete structures. Conventional analysis techniques include, among others, the measurement of electric potential, polarization resistance, and electrochemical impedance spectroscopy (EIS).

The high alkalinity of concrete promotes the formation of a protective layer around the reinforcing steel, which maintains it in a "passive" state. However, the porosity of concrete, fissuring processes and the deterioration of the cement matrix all facilitate the entry of $\mathrm{O}_{2}, \mathrm{CO}_{2}, \mathrm{Cl}^{-}$, and water into the reinforced structures, thereby triggering corrosive processes [2].

In general, it is necessary to analyze each of the resistant sections through the extraction of specimens, which implies working with destructive testing techniques. Often, corrosion is only noted when fissures are observed in the concrete section and the rebars have lost their adherence to the surrounding concrete [3].

A. Rodríguez, S. Gutiérrez-González, V. Calderón Departamento de Construcciones Arquitectónicas, Universidad de Burgos, CNilladiego S/N 09001, Burgos, (Spain)

E-mail: vcalderon@ubu.es

M. I. Prieto, A. Cobo

Escuela Universitaria de Arquitectura Técnica, Universidad Politécnica de Madrid, Avda. Juan de Herrera 6 28040, Madrid, (Spain)
Oxidation and reduction processes in steel cause expansion, which destroys the reinforcing steel and causes cracking in the surrounding concrete. These detrimental processes can be monitored by testing the internal porosity of the reinforced concrete, the loss of section in the rebars, and the stability of the passivation layer at the concrete-steel interface, as well as by checking for fissures or cracks inside the concrete. However, inspecting the inside of a structure is difficult due to the thickness of the layer covering the rebar as well as the dimensions of the resistant sections of the structures. Therefore, many studies have attempted to define these corrosion parameters using nondestructive methods [4,5].

Recycled materials such as ladle furnace slag (LFS) are being increasingly used in cement production, as their use reduces the consumption of natural resources and limits the overall environmental impact of the construction industry. These materials would otherwise be transported to landfill sites for disposal, where they would cause further environmental contamination $[6,7]$.

This study had two main objectives. The first was to test the viability of LFS as a substitute for fines and cement. The second was to evaluate the ability of LFS mortars to resist long-term accelerated corrosion.

The study consists of three sections. The first section describes the manufacturing of mortar specimens containing different quantities of LFS recovered from industrial byproducts. Here, different concentrations of chloride ions were introduced as corrosion accelerators. The second section details the process of subjecting those mortars to accelerated corrosion, qualitatively measuring the parameters that determine both the active and passive states of the materials. Finally, in the third section, the 
microstructure of the specimens was visualized to identify the typical products of corrosion using computerized axial tomography (CT), from which the 3D images were constructed, and scanning electron microscopy (SEM). The results of this work have allowed us to observe the effects of corrosion, to establish a qualitative comparison between recycled and reference mortars, and to assess the efficiency of each analytical method.

\section{Experimental procedure}

\subsection{Materials}

Reference mortar specimens and mortar specimens with different amounts of ladle furnace white slag substituted for Portland cement and fines were prepared for the experimental part of this work. The materials used for specimen fabrication were as follows:

- Portland cement CEM I $42.5 \mathrm{R}$, the properties of which are listed in Table 1.

- Silica sand with an apparent density of $2620 \mathrm{~kg} / \mathrm{m}^{3}$ and a particle diameter of $4 \mathrm{~mm}$. Granulometry are shown in Table 2.

- White LFS recovered from a ladle furnace in the steel refining process. Due to the instability of this waste product, it had to be weathered and repeatedly sprinkled with water, over a period of 2 years, in a process that stabilizes the calcium and magnesium oxides. Weathering transforms the oxides into hydroxides, which helps avoid expansion once the mortars have hardened. Subsequently, the waste was mechanically sieved through a $1 \mathrm{~mm}$ mesh to yield a fine-textured mineral aggregate of a grayish-white color. This material was characterized by X-ray diffraction (XRD) and SEM. The results of this characterization are shown in Fig. 1.

\subsection{Dosage}

The design specifications for both the reference mortar specimens and the LFS mortar were as follows:

- The ratio by weight of ingredient (cement/sand/water) before substitution of the LFS was 1:6:w, where $w$ is the necessary quantity of water needed to reach a good workability that

Table 1. Main properties of Portland cement

\begin{tabular}{lcc}
\hline Test & Value & $\begin{array}{c}\text { Potential composition } \\
\text { of cement with } \\
\text { Bogue method }\end{array}$ \\
\hline Initial setting time & $108 \mathrm{~min}$ & $\mathrm{C}_{4} \mathrm{AF}=10 \%$ \\
Final setting time & $160 \mathrm{~min}$ & $\mathrm{C}_{3} \mathrm{~A}=8 \%$ \\
Density & $3.15 \mathrm{~kg} / \mathrm{dm}^{3}$ & $\mathrm{C}_{3} \mathrm{~S}=61 \%$ \\
Specific surface Blaine & $414 \mathrm{~m}^{2} / \mathrm{kg}^{2}$ & $\mathrm{C}_{2} \mathrm{~S}=19 \%$ \\
Calcination loss & $1.72 \%$ & Others $=2 \%$ \\
Insoluble residue & $0.4 \%$ & \\
Sulfate content $\left(\mathrm{SO}_{3}\right)$ & $3.4 \%$ & \\
\hline
\end{tabular}

Table 2. Sieve size analysis of siliceous sand and LFS

\begin{tabular}{lccccccc}
\hline Diameter (mm) & 4 & 2 & 1 & 0.5 & 0.25 & 0.125 & 0.063 \\
\hline $\begin{array}{l}\text { Siliceous sand } \\
\text { passing (\%) }\end{array}$ & 100 & 80.2 & 60.3 & 33 & 13.3 & 4.0 & 2.6 \\
LFS passing (\%) & 100 & 100 & 100 & 92.7 & 79.2 & 57.6 & 37.6 \\
\hline
\end{tabular}

implies a slump of $175 \pm 10 \mathrm{~mm}$ on the shaking table, per the European Standard [8].

- In the LFS mortars, one part by weight of cement and sand was substituted by LFS. This design was based on earlier works $[9,10]$ in which LFS was substituted for $30 \%$ of the cement and $25 \%$ of the fine sand aggregates.

- To accelerate corrosion, different quantities of $\mathrm{CaCl}_{2}$ were added to obtain percentages of $0,0.4$, and $2.0 \%$ of chloride ions by weight of cement (Table 3).

- $0.5 \%$ SIKATARD setting retardant by weight of cement was added to prolong the workability of the LFS mortar.

\subsection{Mixtures}

The mortar mixtures were prepared in a mechanical mixer by mixing all of the ingredients for $90 \mathrm{~s}$. Subsequently, $(6 \times 8 \times 2)$ $\mathrm{cm}^{3}$ molds were filled in two phases. In the first phase, mortar was poured up to the height of the reinforcement bars and then tamped with a metal rod by applying 25 uniformly spaced blows across the whole surface. In the second phase, three steel bars that were $6 \mathrm{~mm}$ in diameter and $150 \mathrm{~cm}$ in length were positioned so that their full length was embedded in the mortar. The mold was then filled with the rest of the mortar mixture until it was flush with the side, after which it was compacted with an additional series of 25 blows.

The specimens were cured in a humid chamber for $24 \mathrm{~h}$. The molds were then removed, and the specimens were returned to a humid chamber until they had set and were fully hardened.

\subsection{Electrochemical treatment}

Subsequently, the specimens were subjected to accelerated corrosion. Corrosion was quantified by electrochemical tests that measured the corrosion potential $\left(E_{\text {corr }}\right)$ and corrosion rate ( $\left.I_{\text {corr }}\right)$ in a humid atmosphere over 540 days, i.e., a year and a half.

An AUTOLAB/PGSTAT302N potentiostat was used to apply the current. The central rebar of each specimen functioned as the
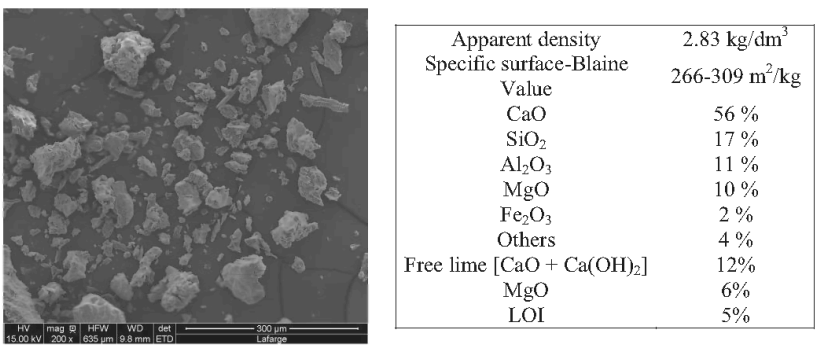

Figure 1. SEM image and chemical composition of ladle furnace slag as raw material 
Table 3. Dosage of the samples with and without LFS

\begin{tabular}{|c|c|c|c|c|c|c|c|c|}
\hline & Cement $(\mathrm{g})$ & Sand $(g)$ & Water $(\mathrm{g})$ & LFS $(g)$ & $\begin{array}{l}\text { Total amount (g) } \\
\text { (without additives) }\end{array}$ & Retardant (g) & $\mathrm{CaCl}_{2}(\mathrm{~g})$ & Ion $\mathrm{Cl}^{-}(\%)$ \\
\hline MCC-0 & 99.6 & 597.5 & 102.9 & - & 800 & 0.50 & 0 & 0 \\
\hline MCC-0.4 & 99.6 & 597.5 & 102.9 & - & 800 & 0.50 & 0.80 & 0.4 \\
\hline MCC-2 & 99.6 & 597.5 & 102.9 & - & 800 & 0.50 & 3.99 & 2.0 \\
\hline MCE-0 & 68.6 & 441.1 & 113.9 & 176.4 & 800 & 0.35 & 0 & 0 \\
\hline MCE-0.4 & 68.6 & 441.1 & 113.9 & 176.4 & 800 & 0.35 & 0.55 & 0.4 \\
\hline \multirow[t]{3}{*}{ MCE-2 } & 68.6 & 441.1 & 113.9 & 176.4 & 800 & 0.35 & 2.75 & 2.0 \\
\hline & \multicolumn{8}{|c|}{ Numerical relationship between different raw materials } \\
\hline & \multicolumn{2}{|c|}{ Cement } & \multicolumn{2}{|c|}{ Sand } & Water & \multicolumn{2}{|l|}{ LFS } & Retardant \\
\hline MCC & \multicolumn{2}{|c|}{1} & \multicolumn{2}{|c|}{6} & 1.03 & \multicolumn{2}{|l|}{-} & 0.005 \\
\hline MCE & \multicolumn{2}{|c|}{1} & \multicolumn{2}{|c|}{6.43} & 1.66 & \multicolumn{2}{|l|}{2.57} & 0.005 \\
\hline
\end{tabular}

working electrode, while the right-hand-side rebar functioned as the counter-electrode, in conjunction with a silver/silver reference electrode (SSCE; $+0.222 \mathrm{~V}$ S.H.E). The cathode electrode consisted of a lead plate placed on top of a wet cloth that was in contact with the mortar (Fig. 2).

The first approximation of the active or passive state of the rebars embedded in the mortar was performed by measuring the corrosion potential or open-circuit potential [ $E_{\text {corr }}$ of the central bar of each specimen in the tests. Likewise, the corrosion rate of the central bar of each specimen was measured by the polarization curve in terms of corrosion intensity $\left[I_{\text {corr }}\right]$.

Due to the slow rate of the corrosion process, an electricity supply was connected to the central bar, making it function as an
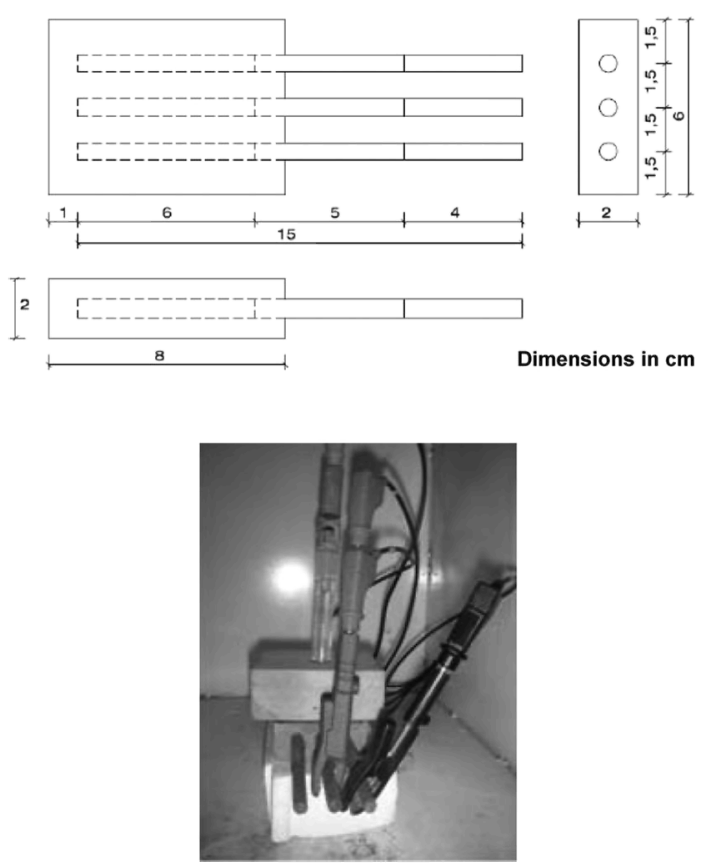

anode. Each bar had a constant current of $1.3 \mathrm{~mA}$, which is equivalent to $10 \mu \mathrm{A} / \mathrm{mm}^{2}$. The measurements were made for three specimens from each dosage. Thus, the results obtained for each mixture were obtained from the mean of all three values.

The states of the specimens after the corrosion tests are shown in Fig. 3.

\subsection{Non-destructive tests}

\subsubsection{Computerized axial tomography (CT)}

CT was used to obtain a quantitative determination of the macroporosity (pore sizes of over $170 \mu \mathrm{m}$ ) and corrosion levels in the mortar specimens [11]. The equipment consisted of an X-ray
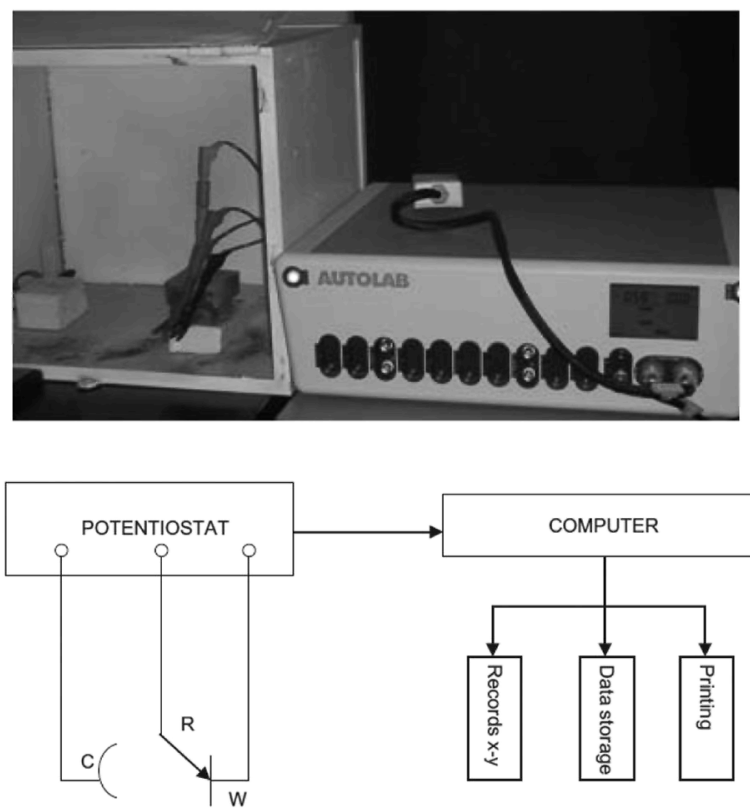

Electrochemical cell

W: Working electrode R: Reference electrode C: Counter electrode

Figure 2. Sample scheme and dimension, and assembly and electricity layout for electrochemical measurement 


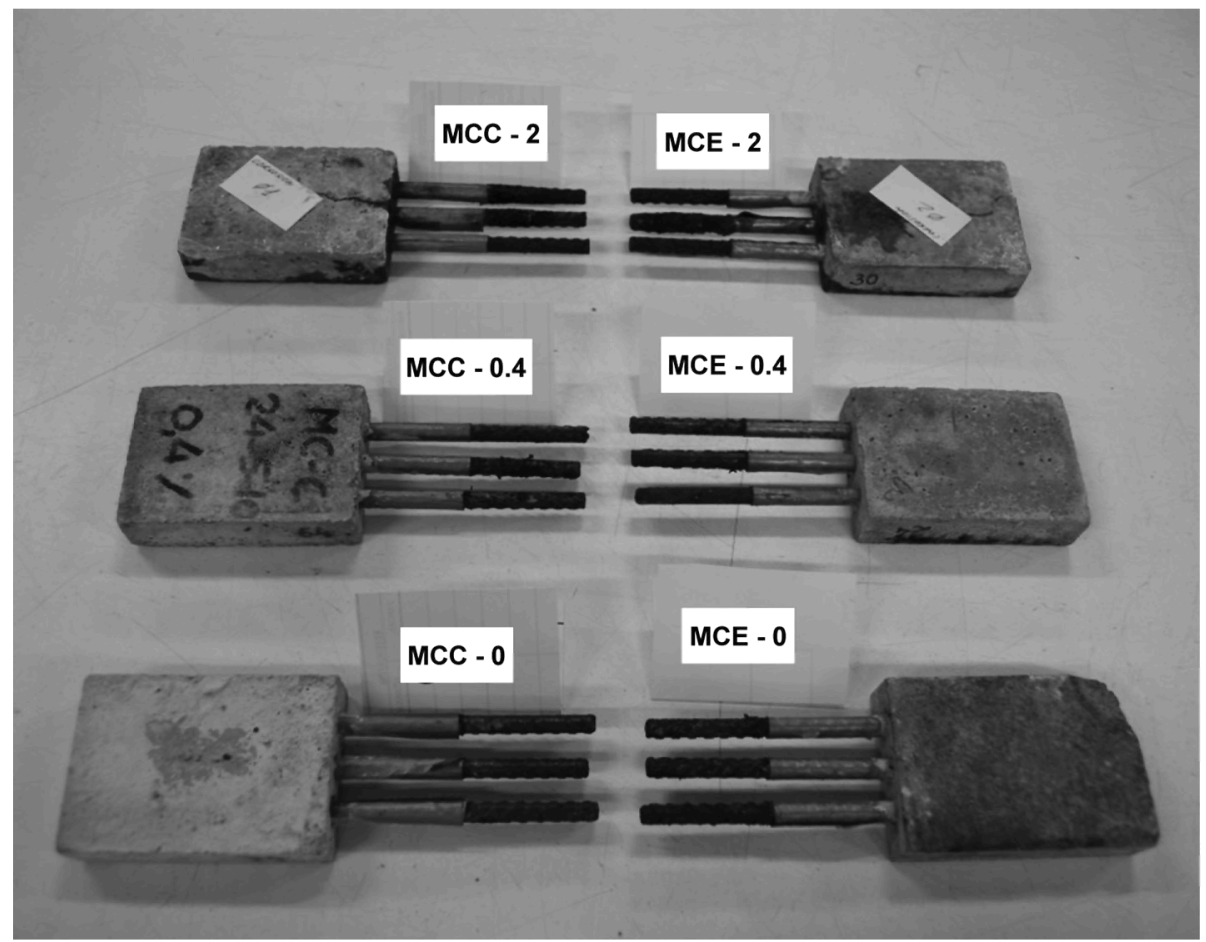

Figure 3. Different dosages of mortar specimens after corrosion test

system with a $225 \mathrm{Kv} / 30 \mathrm{~mA}$ Yxlon tube and a steel-lead-steel cabin, operating with a maximum radiation of $225 \mathrm{Kv} / 30 \mathrm{~mA}$. Image acquisition was completed in $2 \mathrm{D}$ in $0.2 \mathrm{~mm}$ increments, and the images were reconstructed in 3D using the MIMICS 10.0 computer software program.

\subsubsection{Scanning electron microscope (SEM)}

Samples were characterized using a high-resolution scanning electron microscope (SEM JEOL JSM-6460LV) equipped with a INCA-sight LN2 EDS and operating at an accelerating voltage of $15 \mathrm{keV}$ and a current intensity of $1 \mathrm{nA}$.

\section{Results and discussion}

Figure 4 shows the results of the corrosion process for all of the mixtures. In the mixtures without chlorides, the corrosion rate $\left(I_{\text {corr }}\right)$ as a function of time was quicker in the LFS specimens than in the reference mortars. However, all of the values corresponded to the passive state of the rebars. In the LFS samples with chloride concentrations of $0.4 \%$, the results showed low levels of corrosion, although these samples were at the limit of the passive state.

Corrosion rates increased at chloride concentrations of $2 \%$ and became quicker over time, regardless of the amount of added slag. There was a rapid increase in the earlier stages, which later stabilized after 15 days. As expected, the corrosion potential ( $\left.E_{\text {corr }}\right)$ increased in both the reference and the LFS specimens as the amount of chlorides in the mixtures increased. In both cases, the
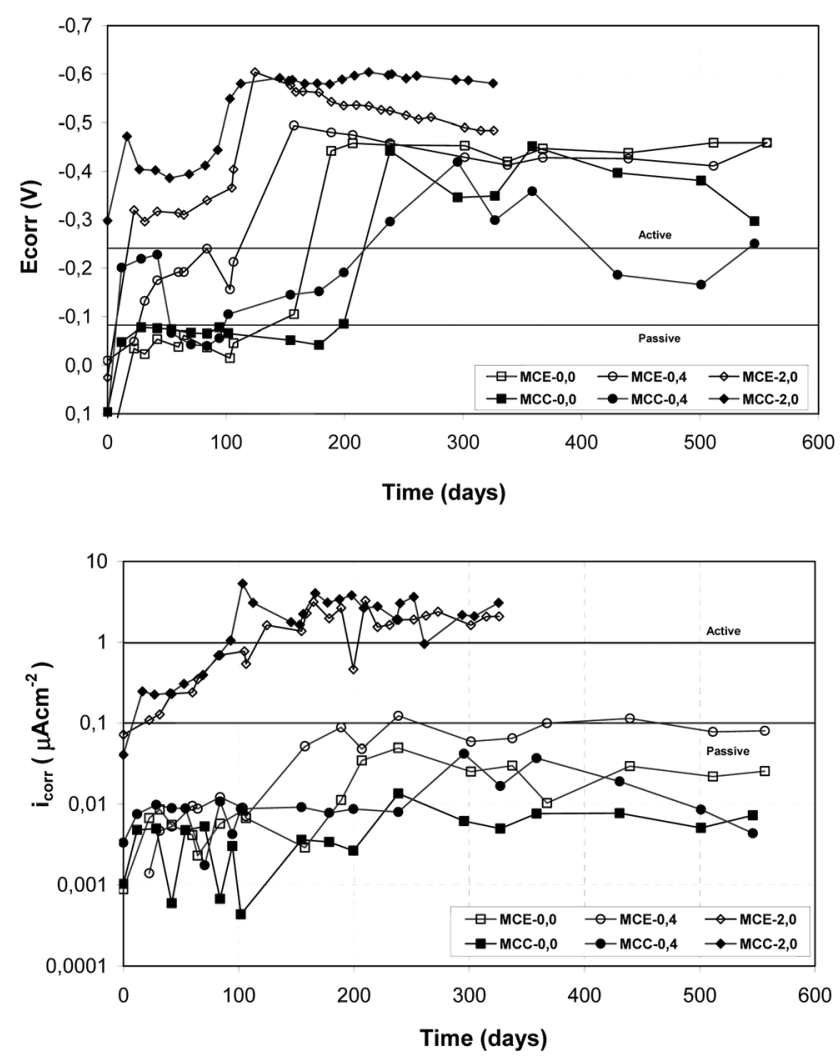

Figure 4. Development of corrosion potential and corrosion rate over time for all the samples, for different percentages of chloride ions 
$\mathrm{MCC}-2$

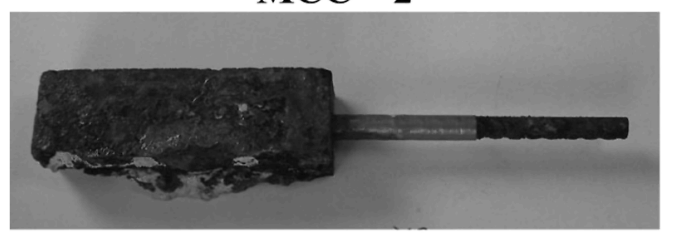

MCE - 2

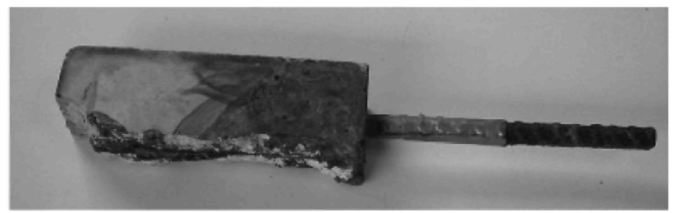

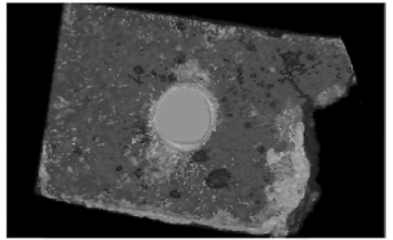

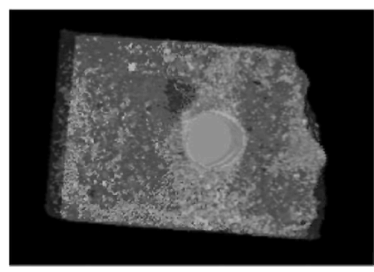

Figure 5. Detail of $3 \mathrm{D}$ reconstruction for MCC-2 ad MCE-2. Yellow corrosion of the samples; gray: cement paste; black: porous

corrosion potential was higher in the early stages. In the case of the recycled mortars, the corrosion potential stabilized after 150 days. In contrast, the corrosion potentials were more variable and stabilized over longer periods in the reference samples.

In addition to the numerical results for corrosion at the different dosages, the effect of corrosion was visualized in areas surrounding the reinforcements and the fissured concrete by a 3D CT image reconstruction $[12,13]$. As an example, in Fig. 5, the natural state of the mortars after they were subjected to the corrosion cycles can be observed. A 3D reconstruction shows the distribution of the deterioration in mixtures MCC-2 and MCE-2. The samples are principally composed of three phases: porosity (black), cement paste (gray), and degree of corrosion (yellow).

When samples MCE-0 and MCE-2, which had the same percentage of slag but had 0 and $2 \%$ of $\mathrm{CaCl}_{2}$, respectively, were examined (Fig. 6), the 3D reconstruction allowed us to observe not only the corrosion but also the condition of the rebars [14]. In the case of specimen MCE-2, it can be observed that a fissure in the matrix caused by accelerated corrosion extends to the surface of the piece due to corrosive products (basically oxides) passing through the fissures to the surface. However, mixture MCE-0 resisted the corrosive process much better, despite being exposed to the same corrosion conditions. These results suggest that the presence of chloride ions substantially accelerated the corrosion process [15].

One theoretical explanation is that the deterioration of the protective rebar passivation layer and the onset of corrosion was facilitated by the active presence of chlorides. The chloride ions would therefore react with the unprotected steel, forming a soluble compound known as iron (II) chloride $\left(\mathrm{FeCl}_{2}\right)$ through the reaction of iron in the steel with chloride anions taken from the calcium chloride $\left(\mathrm{CaCl}_{2}\right)$ in the surrounding concrete. This compound can then interact with oxygen and carbon and form more complex and less soluble steel oxide products [16]. This theory was investigated with SEM, as XRD analysis detected $\mathrm{Fe}$ (II), chloride, oxygen, and carbon cations in some of the fine plaques that formed after the corrosion process (Fig. 7a).

XRD and SEM identified the presence of a large number of $\mathrm{CaCO}_{3}$ crystals (Fig. 7b). The presence of $\mathrm{CaCO}_{3}$ is most likely the result of calcium from the $\mathrm{CaCl}_{2}$ in the matrix combining with water and carbon dioxide in the environment to form calcium carbonate in a carbonation reaction. This reaction would lead to a reduction in the $\mathrm{pH}$ of the medium, which would also favor the break up of the passive layer of the steel and contribute to corrosion [17].

The hydrolysis of the $\mathrm{Fe}$ (II) ions from the $\mathrm{FeCl}_{2}$ is strongly dependent on $\mathrm{pH}$ and is greatly accelerated in highly oxidative media, in which forced hydrolysis occurs until goethite $(\alpha-\mathrm{FeOOH})$ is formed [18]. Although there are various degrees of crystalline reconstruction, in this case, the goethite crystallized in the form of elongated crystals that were several microns in length and nanometers in width and had an orthorhombic space group (Fig. 7c and in further detail in
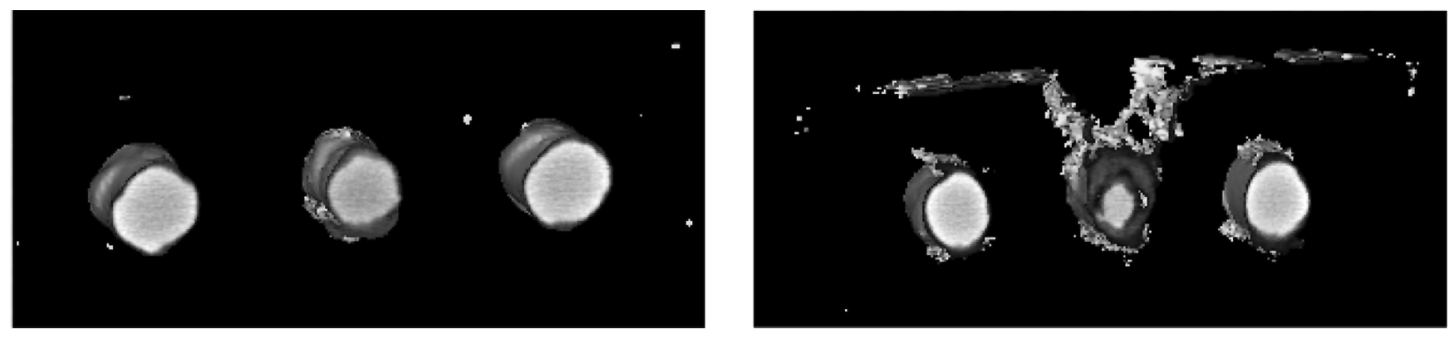

Figure 6. $3 \mathrm{D}$ reconstruction of corrosion for dosages with $2 \%$ of chloride ion. Left: sample MCE-o. Right: sample MCE-2. Yellow: corrosion of the samples; gray: steel bars 

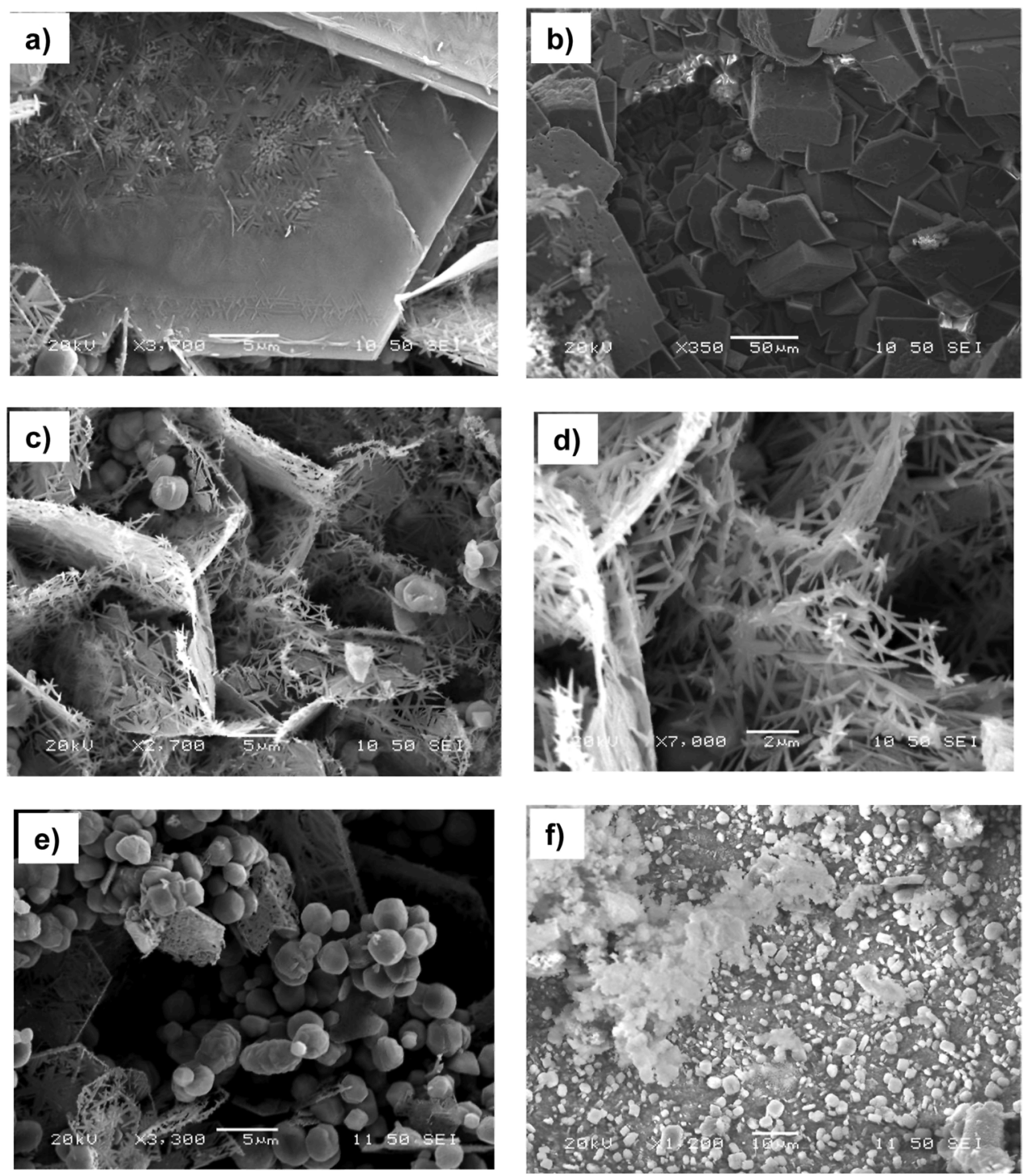

Figure 7. SEM photographs of sample MCE-2 under different magnifications. Detail of oxidize surface boards with (a) $\mathrm{FeCl} 2$; (b) $\mathrm{CaCO}_{3} ;(\mathrm{c}, \mathrm{d}) \alpha-\mathrm{FeOOH}$; (e) $\alpha-\mathrm{Fe}_{2} \mathrm{O}_{3}$ and (f) amorphous $\mathrm{Fe}_{2} \mathrm{O}_{3}$

Fig. 7d). The formation of elongated goethite crystals generally occurs in an alkaline medium, in which chloride ions are reaction activators. Various authors have previously discussed the mechanism by which this crystalline structure is obtained $[19,20]$. Interest in the use and synthesis of goethite for reactions that involve the canalization of numerous compounds is based on the excellent acid-base properties that are generated at the water/goethite interface, which facilitate the absorption of numerous cations and anions.

As the humidity and corrosion conditions were maintained over a prolonged period, the microstructure of $\alpha-\mathrm{FeOOH}$ evolved until different structures of $\mathrm{Fe}_{2} \mathrm{O}_{3}$ were formed by means of a dissolution/reprecipitation process in which the loss of $\mathrm{OH}$ groups occurs during the reorganization of the solid state $[21,22]$. Inspection of the microstructural characteristics of the samples by XRD and SEM confirmed this theory, as the homogeneous, rounded particles were identified as a large number of aggregated $\alpha-\mathrm{Fe}_{2} \mathrm{O}_{3}$, (hematite) particles (Fig. 7e). Other different amorphous nanoparticles of $\mathrm{Fe}_{2} \mathrm{O}_{3}$ were recognizable in the form of a whitish powder of a clearly different structure and size (Fig. 7f).

Although the corrosion products obtained with the different dosages were not quantified, greater amounts of iron oxides were observed in mixtures with higher concentrations of $\mathrm{CaCl}_{2}$. In contrast, the CT technique allowed us to complete a quantitative study in such a way that the combination of both results serves as a reliable method for the analysis of corrosion in mortars manufactured with LFS.

These results fully justify the use of these non-destructive tests for the study of corrosion processes in reinforced mortar.

\section{Conclusions}

We have presented an analysis of the long-term corrosion behavior of different LFS mortar mixtures with embedded rebars that were exposed to a corrosive environment over a period of 1.5 
years. Both electrochemical and microstructural analyses were performed. The results provide the basis for the following conclusions:

- The potential and the rate of corrosion increased with the content of chloride ions in both the reference specimens and the LFS specimens. The mortars with between 0 and $0.4 \%$ chloride remained in the passive state. Only the mixtures with $2 \%$ chloride entered an active state.

- The corrosion products and the size of the fissures originating from within the mortar rebar matrix can be analyzed through non-destructive CT tests without damaging the materials. The influence of the LFS concentration has been shown to increase corrosion and cracking. CT has therefore proven itself to be a convenient technique for the study of steel corrosion in concrete.

- The active presence of chloride ions favors long-term corrosion. The use of SEM has made it possible to identify different crystalline goethite ( $\alpha$-FeOOH needles) and hematite $\left(\alpha-\mathrm{Fe}_{2} \mathrm{O}_{3}\right)$, as well as non-crystalline $\left(\mathrm{Fe}_{2} \mathrm{O}_{3}\right)$ iron oxides that were formed during the corrosion process. The formation of one or the other depended on various factors such as the $\mathrm{pH}$, the humidity, and the concentration of chlorides.

The combination of electrochemical measurements in the microstructural analysis of the steel-to-cement paste interface constitutes a reliable approach that is useful for the characterization of corrosion in mortars manufactured with recycled LFS. Moreover, extrapolation of the results could help us gain a better understanding of the processes that take place during the corrosion of rebars in concrete structures.

\section{References}

[1] M. F. Montemor, A. M. P. Simoes, M. G. S. Ferreira, Cem. Concr. Compos. 2003, 25, 491.
[2] M. I. Prieto, A. Cobo, A. Rodríguez, V. Calderón, Constr. Build. Mater. 2013, 38, 188.

[3] M. Serdar, L. Valek-Zulj, D. Bjegovic, Corros. Sci. 2013, 69, 149.

[4] D. Bernard, D. Chen, N. Burlion, Trans. Eng. Sci. 2003, 43, 2.

[5] A. Cesen, T. Kosec, A. Legat, Corros. Sci. 2013, 75, 47.

[6] C. Junco, J. Gadea, A. Rodríguez, S. Gutiérrez-González, V. Calderón, Cem. Concr. Compos. 2012, 34, 1174.

[7] S. Gutiérrez-González, J. Gadea, A. Rodríguez, M. T. BlancoVarela, V. Calderón, Constr. Build. Mater. 2012, 34, 179.

[8] EN 1015-3, Methods of test for mortar for masonry. Part 3. Determination of consistence of fresh mortar, 1999.

[9] J. M. Manso, A. Rodriguez, A. Aragón, J. J. Gonzalez, Constr. Build. Mater. 2011, 25, 3508.

[10] A. Rodríguez, S. Gutiérrez-González, M. Horgnies, V. Calderón, Mater. Des. 2013, 52, 987.

[11] M. Beck, J. Goebbels, A. Burkert, Mater. Corros. 2007, 58, 207.

[12] M. Beck, J. Goebbels, A. Burkert, B. Isecke, R. Bäßler, Mater. Corros. 2010, 61, 475.

[13] I. Tekin, R. Birgul, H. Yilmaz Aruntas, Constr. Build. Mater. 2012, 35, 15.

[14] H. Elaqra, N. Godin, G. Peix, M. R’Mili, G. Fantozzi, Cem. Concr. Res. 2007, 37, 703.

[15] D. A. Koleva, J. Hu, A. L. A. Fraaij, P. Stroeven, N. Boshkov, J. H. W. de Wit, Corros. Sci. 2006, 48, 4001.

[16] R. M. Cornell, U. Schwertmann, The Iron Oxides, Structure, Properties, Reactions, Occurrences and Uses, Wiley-VCH, Weinheim 2003.

[17] J. Zhang, F. J. Martin, Mater. Corros. 2013, 64, 388.

[18] M. Ristic, I. Opacàk, S. Music, J. Alloys Compd. 2013, 559, 49.

[19] S. Krehula, S. Popovic, S. Music, Mater. Lett. 2002, 54, 108.

[20] S. Krehula, S. Music, J. Cryst. Growth 2008, 310, 513.

[21] M. Ristic, S. Music, M. Godec, J. Alloys Compd. 2006, 417, 292.

[22] M. Zic, M. Ristic, S. Music, J. Mol. Struct. 2007, 834-836, 141.

(Received: March 7, 2014)

W7697 